\section{Public Health Genomics}

Public Health Genomics 2011;14:115-124

DOI: $10.1159 / 000314915$
Received: December 7, 2009

Accepted after revision: May 6, 2010 Published online: August 13, 2010

\title{
Public Understanding of Risks from Gene- Environment Interaction in Common Diseases: Implications for Public Communications
}

\author{
C.M. Condit L. Shen \\ Department of Speech Communication, University of Georgia, Athens, Ga., USA
}

\section{Key Words}

Gene-environment interaction - Genetic literacy - Genetics education - Public understanding of genetics $\cdot$ Public understanding of science $\cdot$ Risk perception $\cdot$ Synergistic risk

\begin{abstract}
Background/Aims: Public understanding of the relationship between health behaviors and genes is likely to affect the motivational impact of learning information about one's own genes. Extant research has featured difficulty measuring public understandings of this relationship. This essay explores public understanding of the relationship between genes and behavior, especially with regard to the mathematical relationships to risk concept. It contributes a psychometrically valid scale for measuring beliefs about genebehavior relationships. Methods: Three population representative surveys ( $n=633,658,1,218$ ) were conducted using the Knowledge Networks panel platform. Results: Interpretations of risk vary depending on whether genes and behavior are conceived of as health-damaging (loss frame) or health-protecting (gain frame). In the loss frame, the majority of the population adopts an additive model of the relationship with approximately one-third adopting an amplificative model. In the gain frame, beliefs are divided roughly equally among additive, amplificative and sub-additive
\end{abstract}

models. Scores on the nonmathematically based scale indicate higher belief in the existence of interaction than scores on the more concrete question format. Conclusions: The existence of different interpretations of gene-behavior relationships based on gain/loss frame and abstract/concrete modes indicates the need to select frame and mode carefully in both teaching and research. Research is needed to identify optimal configurations for teaching and presenting this relatively complex material.

Copyright $\odot 2010$ S. Karger AG, Base

\section{Introduction}

Personalized genetic testing is one of the major applications by which genetics research has been predicted to benefit human health. Supporters project that such testing will inform individuals about their personal risks and thereby facilitate behavior change. As Francis Collins [1], then director of the National Human Genome Research Institute, explained to the U.S. Congress in 2003, in the next ten years 'predictive genetic tests will exist for many common conditions in which interventions can alleviate inherited risk, so that each of us can learn of our individual risks for future illness and practice more effective health maintenance and disease prevention.' Recently,

\section{KARGER}

Fax +4161306 1234

E-Mail karger@karger.ch

www.karger.com (c) 2010 S. Karger AG, Basel

Accessible online at: www.karger.com/phg
Celeste M. Condit

Department of Speech Communication, University of Georgia 110 Terrell Hall

Athens, GA 30602-1725 (USA)

Tel. +1 706542 7863, Fax +1 706542 3450, E-Mail ccondit@uga.edu 
what has come to be called 'direct to consumer' testing has brought this future prediction into the present for a modest number of people $[2,3]$, and these services have now entered mainstream medicine, as organizations such as Toronto's Medcan Clinic has announced it will offer Navigenics testing to its clients [4]. The efficacy of such personalized genetics depends, however, upon the assumption that information that one is personally at risk will motivate behavior change. There is yet insufficient knowledge about the motivational dimensions of this information. As Heshka et al. [5, p. 30] conclude in their systematic review of behavior change resulting from genetic testing, 'it is unclear how best to present information on genetic predisposition to patients.' The best means for presenting information depend in part on what the public already believes.

A substantial research base is developing on public understanding [6,7] and public communication [e.g. 8-11] of genetics. These studies, along with more general studies of understandings of health causation [12], have indicated that lay people tend to attribute health outcomes to both genes and behavior, although with different degrees of influence for each depending on specific conditions [13-15]. These results have warranted studies focusing more precisely on how the public understands the relationships of genes and behavioral choices. This relationship is understood in the scientific literature under the rubric of 'gene-environment interaction.'

\section{Scientific Basis of Gene-Behavior Interactions}

Although several recent reviews have demonstrated the difficulties involved in establishing gene-environment interactions scientifically [16-19], there appears to be a consensus that it is reasonable to presume that such interactions exist. As Zubrick et al. [20] have indicated, 'It is now recognized that most of the diseases that represent a significant burden to human population are multifactorial. Many are caused by the joint action and interaction of genes and environment, this is what is meant by a "complex" disease.' Sing et al. [21, p. 1190] have agreed, suggesting that 'every medical researcher knows' that 'meaningful insights into the role of [genomic] variation requires a biological model of genome-phenotype relations that incorporates interactions between subsets of possible genetic and environmental agents as causations in particular contexts indexed by time and space.' Khoury and Wacholder [16] have reported that about $14 \%$ of studies related to genes published between 2001 and 2009 focused on gene-environment interaction.

\section{Terminology}

Despite this general scientific consensus, confusion exists about key terms such as 'multiplicative' and 'additive' interactions [22]. This confusion may be exacerbated by different research goals (e.g. identifying relationships between genes and behavior as opposed to motivating behavior change by use of genetic tests). For the purposes of health behavior promotion by means of genetic testing, an interactive perspective is more desirable than a subadditive or even additive perspective because an interactive perspective entails the possibilities both that behavior can change health outcomes and that health behaviors may have particular and more substantial impacts for those who have increased risks because of their genes. Because of the confusion implicit in the term 'multiplicative' identified by Silberberg [23], we use the term 'amplificative' to indicate greater than additive interactive effects. The term 'additive' is here used to indicate a mathematical relationship in which the risks (usually odds ratios) of having one risk-increasing genetic factor and one risk-increasing environmental factor (compared to the general population) are approximately equivalent to the sum of the risks from having only one of each of these factors at a time. This is understood as a 'noninteractive' perspective on gene-environment relationships. A 'subadditive' relationship is technically an 'interactive' relationship, but it is generally viewed as working against health behavior promotion effects from genetic testing.

\section{Qualitative Research on Public Understanding of Gene-Environment Relationships}

Preliminary work exists regarding the issues of public understanding of gene-environment interaction [24-27], public education about gene-environment interaction $[28,29]$ and the impacts of public messages about geneenvironment interaction [30]. This research has tentatively addressed both the qualitative and quantitative dimensions of public understandings of the gene-environment relationship. Qualitative analysis has suggested that the public generally treat genes and behavior separately, rather than simultaneously [25]. This 'separate tracks' model is consonant with findings by Morris et al. [31], who found a resistance among the public to identifying genetic components in health outcomes identified as environmental. Condit et al. [25] and Gronnvoll and Landau [27] found that, in the relatively rare cases where genes and behavior were articulated in interaction with 
each other, participants used various metaphors for understanding genes. These included 'virus,' 'trigger' or 'bomb' metaphors, which portrayed genes as lying latent or dormant and then being activated by a specific exposure as well as behaviors adding 'fuel to the fire' of genetic backgrounds.

\section{Research on the Quantitative Dimensions of Public Understanding}

The only located published study that directly analyzed public understandings of the quantitative dimensions of gene and behavior interaction concluded that the public does not have a model of 'synergistic' (i.e. interactive) effects of combined family history and environmental exposure, but rather applies a sub-additive model. Using a between-subjects design, French et al. [26] asked participants in 2 studies - 1 consisting of college students and 1 consisting of heart disease patients - to indicate the likelihood that a man would get a heart attack. Participants rated 1 of 4 vignettes composed of the 4 permutations of the 2 variables (1) having or not having a family history and (2) high and low smoking. The participants rated those smoking or with a family history as highly likely to have a heart attack. However, the risk ratings did not increase for those with both a family history and smoking. This is called a sub-additive model because the risk ratings for someone with both factors were mathematically lower than the amount that would result from adding the risk rating for family history to the risk rating for smoking. These findings were consistent with most previous studies of public understandings of combined risks that did not conclude genetic factors [32, 33].

These studies thus showed either additive or sub-additive mathematical models among the public when they combine causative factors to assess risk. As French et al. [26] noted, however, these results could be the consequence of the measurement approaches, which generally asked people to rate risks on a low to high scale. Because people placed the risk levels for family history and smoking (or other single factors) at very high levels, there was no room to reflect a synergistic effect mathematically (a 'ceiling' effect). This possibility was reinforced by a study of risk estimates related to smoking and radon by Eiser et al. [34], which used a different methodology and which did identify synergistic effects for these 2 nongenetic factors. Subsequently, Hampson et al. [35] compared the use of a Likert-style scale to an anchored relative scale in responses to nongenetic risk. They found synergistic effects using the anchored scale, but not the Likert scale, for a familiar pair of risks that they rated as high synergy but not for a nonfamiliar pair of risks that they rated as high synergy or for a familiar pair of risks that they rated as low synergy. Given that most genetic risks may fall in the nonfamiliar zone, this scale may not be sensitive enough for genetics studies.

A second feature identified by the existing literature is the contextual variability of the ratings, which may suggest that motivations play a role in the ratings given. For example, Hampson et al. [32] found that smokers gave lower ratings to risks to the members of their household resulting from their own smoking than they gave to themselves or to the neighborhood or general public. Condit et al. [25] also suggested that people's choice of models of causation - whether genes, behavior, or both - was dependent on context. This suggests the need to attend to the influence of motivational factors in such ratings.

Finally, the existing literature indicates that responses to the gene-environment interaction concept are dependent on the particular mode of presentation. Kaphingst et al. $[28,29]$ found that an 11-12 minute didactic presentation was more successful than a comparable activelearning session at teaching the model in a virtual reality environment and that the content of the metaphor used to present the information (elevator vs. bridge) also effected the level of change in understanding.

\section{Preview}

Taken together, the research stream thus indicated the need to explore alternative ways of measuring understandings of gene-behavior relationships that included both qualitative and mathematical dimensions and that assessed content- and context-sensitivity. At different phases of the research project, we explored multiple dimensions of content- and context-sensitivity, including variation by specific disease, variation by self vs. other framing and alternative metaphors. In addition, because framing a health message as a 'gain' from improved behavior as opposed to framing it as a 'loss' from bad behavior has been shown to be consequential in other health messages $[36,37]$ and because gain/loss framing choices must be made in the presentation of genetic information for the purpose of modifying behaviors, we also explored the impact of gain vs. loss framing. As the project progressed, we focused on heart disease because it was too difficult to include multiple diseases in short messages. 
Heart disease was the most familiar to participants and was generally perceived as having both genetic and behavioral components (as opposed, for example, to lung cancer, which was perceived as heavily behavioral). We also came to focus the scale on general rather than personal questions because of the psychometric properties of those questions. We here present the 'Gene-Behavior Interaction Beliefs Scale', which we suggest is a reliable but still preliminary tool for measuring a qualitative understanding of gene-behavior interaction. We also present a pair of questions that provide a novel way of measuring understandings using a quantitative rubric (hereafter the 'additive/amplificative test questions'). The latter shows content-sensitivity in terms of gain and loss framing. We report public understandings of the relationships between genes and behaviors based on these 2 measurement tools. In the discussion, we point to possible explanations and next steps for dealing with the apparent complexity of attitude structures relating to gene-behavior interaction.

\section{Method}

This article reports data from 3 studies. All were approved by the Institutional Review Board and all participants gave informed consent. Studies A and B were designed to compare the effects of behavior-only and gene-behavior interaction messages presented in a video format (there were no effects of the messages on the attitudes measured and reported here), and study $\mathrm{C}$ was a simple belief survey. Studies A and B included 2 demographic questions (U.S. Census-style race and ethnicity), the fatalism scale (e.g. 'How long I live is a matter of luck,' 'If someone gets a serious disease, that's the way they were meant to die') [38], the genetic determinism scale (e.g. 'The genes one is born with determine how healthy one will be throughout life,' 'Genes are more important than one's own behavior in determining one's health', a shortened version from [39]), the Gene-Behavior Interaction Beliefs Scale (fig. 1), the additive/amplificative test questions (table 1: question 1 in study A, and both questions 1 and 2 in study B), some health belief questions (e.g. efficacy of eating fruits and vegetables), and 5 questions related to the 2 specific messages (e.g. novelty, motivation to take action, change behavior, learn more information, and feelings of control over behavior). Study $\mathrm{C}$ included different versions of the scales (more extended in the case of determinism, overlapping but not identical in the case of gene-behavior interaction; see table 1 questions 3 and 4 for two relevant examples) as well as additional health belief questions.

Studies A, B, and C were 3 nonoverlapping samples of the general public surveyed via Knowledge Networks' general population panel. The panel is recruited via telephone to represent the general population. To ensure adequate representation of all demographic groups - including difficult to enroll minorities, low income and low education sectors - participants are web-enabled by the research organization. Panel members gain points for participating in multiple surveys, based on the difficulty of the sur-

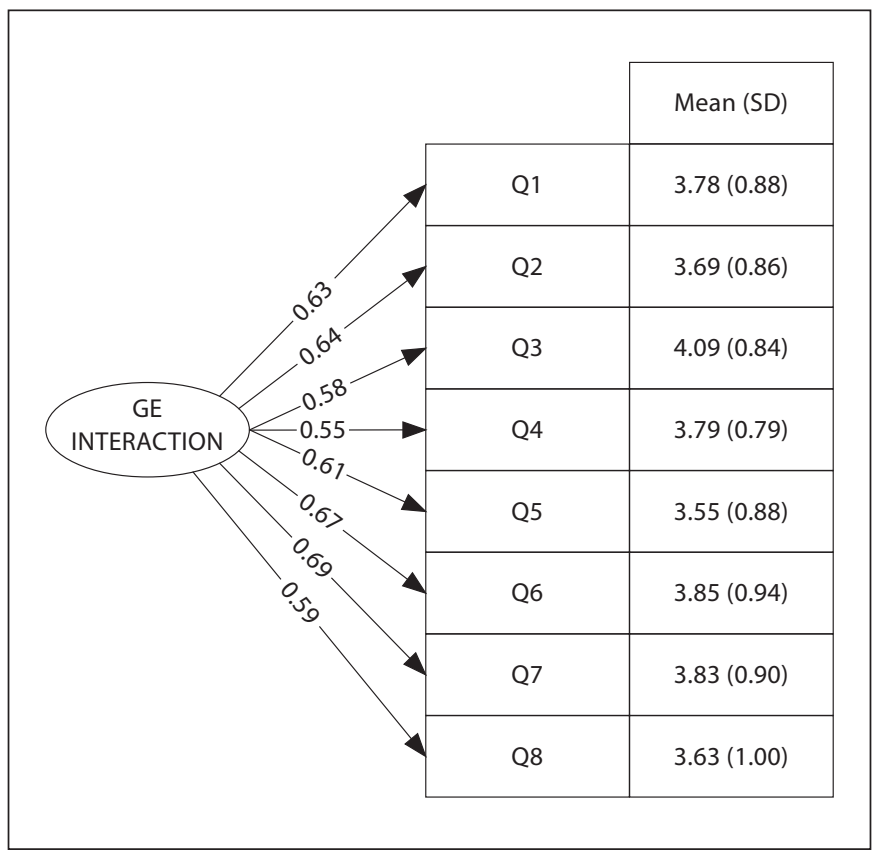

Fig. 1. Questions, descriptives and factor structure for GeneBehavior Interaction Beliefs Scale. 1 = Unhealthy behaviors increase the risk of disease more for people who have a gene for that disease than for other people. 2 = People's behaviors influence the effect that their genes have on their health. $3=$ Genes and behaviors interact to shape your health. $4=$ Healthy behaviors can slow down the effects of unhealthy genes a lot. $5=$ A person's behavior can increase or decrease the expression of particular genes they have. 6 = Unhealthy behaviors make the risk of disease skyrocket for people who have a gene for a disease. $7=$ Unhealthy behaviors accelerate the effects of unhealthy genes a lot. $8=$ Unhealthy behaviors make the effects of unhealthy genes snowball to produce disease.

veys (but approximately equivalent to 2 USD per survey), but they are not required to participate in any particular survey, and they underwent separate consent processes for the general participation in the panel and then again specifically for each of these studies. These panels have been shown to provide relatively good representation of the general public's beliefs because they combine the positive effects of online surveys with the greater representativeness of phone solicited participation through the process of web enablement $[40,41]$, and in these 3 studies cooperation rates exceeded $72 \%$.

In addition to the data reported here, the scales and questions were the product of extensive prior formative research. These included 6 focus groups, 13 cognitive interviews, 2 small-N pilot tests on the Knowledge Network platform as well as quantitative studies with nongeneral population samples. First, large numbers of questions were generated by combing the interviews described in Condit et al. [25] for potential questions and through brainstorming and evaluation sessions with a multi-cultural Community Advisory Board. Questions were then further assessed for 
Table 1. Additive/amplificative test questions and results

\section{Question 1}

Imagine a person named R.J. R.J. has a version of a gene that increases the chance of getting a heart disease by $20 \%$. R.J.'s food habits also increase the risk for a heart disease by $20 \%$. Considering that R.J. has both the gene and the unhealthy food habits, how much is R.J.'s risk for heart disease increased?
A. The risk is increased by $40 \%$.
Study A
$323(51.0)$
Study B
$336(51.1)$
B. The risk is increased by more than $40 \%$.
Study A $236(37.3)$
C. The risk is increased by less than $40 \%$.
Study B $249(37.8)$
Study A $\quad 62(9.8)$
Study B $65(9.9)$

Question 2

Imagine another person named C.W. C.W. does not have the version of the gene that R.J. has. C.W. also has totally healthy food habits. Considering that C.W. does not have the risky gene, and with healthy food habits, how much is C.W.'s risk for heart disease decreased compared to an average person?
A. The risk is decreased by $40 \%$.
Study B $213(32.4)$
B. The risk is decreased by more than $40 \%$.
Study B $201(30.5)$
C. The risk is decreased by less than $40 \%$.
Study B $225(34.2)$

Question 3

Emmeline Smith is 92 years old. She has smoked cigarettes all her life. She eats high fat foods, and she has never gotten any physical activity. Why do you think she has never gotten cancer, heart disease or adult diabetes? Please rank all the reasons you think are true (with 1 being the biggest reason).
A. Her genes do not make her susceptible to these diseases.
Study C
$351(28.8)$
B. A Higher Power wanted her to live a long time.
Study C $255(20.9)$
C. She is lucky.
D. This was just her fate.
Study C $\quad 98(8)$
Study C $68(5.6)$
E. Her genes allow her to process these bad substances easily.
Study C
$236(19.4)$
F. There is no explanation for this.
Study C
$119(9.8)$
G. Other
Study C
$19(1.6)$

Question 4

Sarah Jones dies at age 45 from a heart attack. She exercised regularly. She ate a healthy diet. She never smoked. Why do you think she died at this age? Please rank all the reasons you think are true (with 1 being the biggest reason).
A. Her genes made her susceptible to these diseases.
Study C
$493(40.5)$
B. A Higher Power determined it was her time.
Study C
$289(23.7)$
C. She was unlucky.
D. This was just her fate.
Study C $29(2.4)$ E. Her genes could not process even a small amount of bad
substances well.
Study C
$81(6.7)$
F. There is no explanation for this.
Study C
$104(8.5)$
G. Other
Study C
Study C
$117(9.6)$
$39(3.2)$

Data in parentheses are percentages.

clarity via the cognitive interviews, for content validity via the focus groups (through a comparison of qualitative responses and the quantitative measures being tried out), and for reliability and coherence via reliability analysis and exploratory factor analysis in the nontarget audience quantitative studies. We report here the results of confirmatory factor analysis on the gene-environment interaction scale in studies $\mathrm{A}$ and $\mathrm{B}$, frequencies of answers selected in studies A, B and C and regression analysis to assess the impact of gender and race on frequency of models selected in the quantitative-format questions.

Public Understanding of

Gene-Environment Interaction

\section{Results}

Demographic information for participants in all 3 studies is reported in table 2.

\section{A Non-Numeric Approach: The 'Gene-Behavior \\ Interaction Beliefs Scale'}

Through the multiple stage formative research process, we sought to develop a scale that would capture 
Table 2. Gender, education, age, and race/ethnicity of participants

\begin{tabular}{|c|c|c|c|}
\hline Study (year) & $\mathrm{A}(01 / 29 / 09-02 / 16 / 09)$ & B $(04 / 08 / 09)$ & $\mathrm{C}(06 / 26 / 07-07 / 22 / 07)$ \\
\hline Total participants & 633 & 658 & $\begin{array}{l}1,218 \\
\text { (824 general population with } 197 \\
\text { Hispanic oversample and } 197 \text { African } \\
\text { American oversample) }\end{array}$ \\
\hline Gender & $\begin{array}{l}\text { M } 308 \text { (48.7) } \\
\text { F } 325(51.3)\end{array}$ & $\begin{array}{l}\text { M } 336(51.1) \\
\text { F } 322(48.9)\end{array}$ & $\begin{array}{l}\text { M } 587 \text { (48.2) } \\
\text { F } 631(51.8)\end{array}$ \\
\hline Race/ethnicity & $\begin{array}{l}\text { White, non-Hispanic } 465(73.5) \\
\text { Black, non-Hispanic } 66(10.4) \\
\text { Other, non-Hispanic } 18(2.8) \\
\text { Hispanic } 63(10) \\
2+\text { races, non-Hispanic } 21(3.3)\end{array}$ & $\begin{array}{l}\text { White, non-Hispanic } 470(71.5) \\
\text { Black, non-Hispanic } 60(9.1) \\
\text { Other, non-Hispanic } 19(2.9) \\
\text { Hispanic } 81(4.3) \\
\text { 2+ races, non-Hispanic } 28(4.26)\end{array}$ & $\begin{array}{l}\text { White, non-Hispanic } 607(49.8) \\
\text { Black, non-Hispanic } 272(22.3) \\
\text { Other, non-Hispanic } 27(2.2) \\
\text { Hispanic } 289 \text { (23.7) } \\
\text { 2+ races, non-Hispanic } 23(1.9)\end{array}$ \\
\hline Age & $\begin{array}{lc}18-24 & 53(8.37) \\
25-34 & 95(15.02) \\
35-44 & 109(17.22) \\
45-54 & 135(21.33) \\
55-64 & 122(19.27) \\
65-74 & 80(12.64) \\
75+ & 39(6.16)\end{array}$ & $\begin{array}{lc}18-24 & 60(9.12) \\
25-34 & 84(12.77) \\
35-44 & 107(16.26) \\
45-54 & 127(19.30) \\
55-64 & 139(21.2) \\
65-74 & 97(14.74) \\
75+ & 44(6.69)\end{array}$ & $\begin{array}{lc}18-24 & 122(10.02) \\
25-34 & 188(15.44) \\
35-44 & 262(21.51) \\
45-54 & 258(21.28) \\
55-64 & 202(16.58) \\
65-74 & 119(9.77) \\
75+ & 67(5.50)\end{array}$ \\
\hline
\end{tabular}

Data in parentheses are percentages.

(1) the concept that genes and environment work in relationship to each other rather than independently (questions 2, 3 and 5, fig. 1), (2) a nonmathematical sense of an amplificative relationship (all other questions, fig. 1) and (3) that included both loss (unhealthy, Q1, 6, 7, 8) and gain (healthy, Q4) frames. The scale consisted of five 1-5 point Likert scale items $(1=$ strongly disagree, $5=$ strongly agree). This scale was used in both studies A and B. Confirmatory factor analysis using LISREL 8.70 showed that the scale was uni-dimensional in both studies. The model fit indices were: d.f. $=20$, chi-square $=95.53$, RMSEA $=0.07$, GFI $=0.96$, CFI $=0.97$ from study A and very similar from study $\mathrm{B}$. The scale also demonstrated high reliabilities in both studies (Cronbach's alpha, study $\mathrm{A}=0.832$; study $\mathrm{B}=0.828$ ). The scale also successfully predicts the answer to the more mathematically oriented additive/amplificative test questions: the biserial correlation between the scale and the loss framed (R.J.) question was $r=0.10, p<0.01$ from study A. In study B, the biserial correlation was $0.09(\mathrm{p}<0.05)$ for the loss framed (R.J.) question, and $0.08(\mathrm{p}<0.05)$ for the 'gain' framed
(C.W.) question. The scale thus appears to have several desirable properties. However, in both study A and B, the public reported relatively high levels of belief in gene-environment interaction as measured by the scale (greater than 3.77 on a 5 point scale, $1=$ strongly disagree, $5=$ strongly agree).

\section{Additive vs. Amplificative Test Questions and Quantitative Beliefs}

In study $A$ and $B$, we asked the mathematically framed questions we had designed through the multi-stage formative research (the additive/amplificative test questions ('R.J.' and in study B also 'C.W.'): see table 1, questions 1 and 2) to directly assess whether participants believed in an amplificative model of the mathematical effect characteristics of the relationship of genes and environment on health. These questions were designed to avoid the problems of ceiling effects seen in the prior research. These questions do not seek to gain an 'accurate' estimate of a particular gene-environment relationship (a question that in most cases remains empirically unknown at this 
time). Instead, the goal was to assess whether, when faced with a question about quantitative relationships, people intuitively assumed a sub-additive, additive, or amplificative relationship. In the formative research phase, we tried multiple formats for assessing this intuitive sense (including procedures similar to those reported by earlier researchers, with some changes in response options, etc.). Although it may seem difficult, this question was responded to easily and comfortably by participants in pretest cognitive interviewing and was refused by less than $2 \%$ of participants in these 2 studies. The question and the results in the 2 studies (table 1) are consistent. They indicate that a bare majority of the population understands the combining of risks from genes and behavior as producing additive amounts of risk (i.e. 'The risk is increased by $40 \%$ '). Well more than a third, however, understand these risks as amplificative (i.e. 'The risk is increased by more than $40 \%$ '). A small minority understands the risks as sub-additive ('The risk is increased by less than 40\%').

To check if any of the demographic variables might be predictors of whether individuals responded to these questions with the interactive answer, the following analyses were conducted: First, we recoded the loss framed question (R.J.) into a binary variable, i.e. if an individual chose the amplificative answer, the response was coded as accurate $(=1)$; otherwise, the response was coded as inaccurate $(=0)$. A binary logistic regression model was estimated using the demographic variables to predict the recoded loss frame (R.J.) question. In both studies, none of the demographic variables (age, gender, race, education, and income) emerged as a significant predictor of whether they responded accurately to the loss framed R.J. question with the interactive answer.

\section{The Impact of Gain vs. Loss Frame on Expressed \\ Beliefs}

Because previous studies had suggested contextual effects and because message framing has shown different effects arising from whether messages are framed as 'gain' or 'loss' [36, 37], we addressed the issue in 2 additional ways. In study B, we asked a question that was as close to the loss framed R.J. question as feasible, but which framed the question in terms of the gain in health that one would expect from good genes and improved behavior. That question, using the gain frame, produces different results from the loss frame (table 1). The message framing condition was entered as an additional predictor in the binary logistic regression model. The loss frame R.J. question led to significantly higher choice of the in- teractive option $(37.8 \%)$ than the gain frame C.W. question (30.5\%): $\beta=0.33, p<0.01$. With the gain frame C.W. question, roughly similar proportions of the population endorse each option. They not only move away from the amplificative response but also away from the additive response, toward a sub-additive model. Because there are different potential accounts for this difference, we also report the results of an analogous but somewhat differently structured question pair (table 1: questions 3 and 4).

Study $\mathrm{C}$ was conducted prior to $\mathrm{A}$ and $\mathrm{B}$, and these 2 questions were not retained in later studies, because of their complexity. However, they are informative given the findings from study $B$. The 2 questions asked participants to provide causal accounting for instances that come up frequently in interviews about health causation - the person who either violates all health behavior recommendations and lives a long and healthy life (e.g. 'My grandmother smoked all her life and lived to be $90^{\prime}$ ) or who follows all health behavior recommendations and dies young (e.g. Christopher Reeves' nonsmoking wife dying of lung cancer). The questions are as indicated in table 1 (questions 3 and 4) with the result being the number of persons who ranked this cause as number 1 .

Again, the answers differ depending on whether genes are understood as causing bad health (Sarah, a loss frame) or contributing to good health (Emmeline, a gain frame). The participants see genes as having a greater impact on disease than on health ( $40.5 \%$ list genetic susceptibility as the No. 1 cause in the loss frame, whereas $28.8 \%$ list this in the gain frame; Pearson chi-square $=3.969 \mathrm{E} 2$; $\mathrm{p}<$ $0.000)$. Participants also endorse a process account of an interaction effect (answer E) twice as often in the gain frame $(19.4 \%)$ as in the loss frame (8.5\%) (Pearson chisquare $=2.552 \mathrm{E} 2 ; \mathrm{p}<0.000$ ).

\section{Discussion}

This project sought to identify ways of measuring lay beliefs about the relationship of genes and behavior that did not face the limitations identified in previous measurement attempts (presumed to be primarily ceiling effects). As we began the project, we assumed that it would be possible to use standard scale-building methods to construct a nonquantitatively explicit, reliable and unidimensional scale that would capture the desired content dimensions of the gene-behavior interaction concept (interaction, amplificative relationship and transitive relationship of healthy/unhealthy). We presumed that such a scale would be roughly isomorphic with direct measures 
that included quantitative estimates. We pursued measurement strategies in both quantitatively explicit and nonquantitatively explicit modes and produced independent measurement tools (the 'Gene-Environment Interaction Scale' and the additive/amplificative test question pair). However, although the scale has good psychometric properties, it is only weakly correlated with the latter, more direct quantitative measurement tool.

This research thereby has identified several challenges for the development of optimal means of communicating with the public about gene-behavior interaction. This discussion will first address the issue of the beliefs as measured and then address issues related to the need for future scale development (including limitations of this reported research project).

This research suggests that substantial segments of the public harbor different views of the relationship between genes and behavior. As measured via the gain framed additive/amplificative test question (R.J.), about a third of the population endorses an amplificative model, but the largest segment appears to hold a mathematical model that is additive rather than interactive, and there is also a small minority that endorses a sub-additive model. As measured by the scale, on the other hand, the mean answer leans toward acceptance of an amplificative account. Both of these results are different from those of the prior research garnered using the contrasts between numeric scales, which identified the sub-additive model as the dominant understanding. Our results, thus, support French et al.'s [26] suggestion that the earlier results were produced by a ceiling effect inherent to the measurement approach used there. The present results also are consonant with the qualitative research on lay people's discourse, which showed a predominant separate tracks model but some interactive metaphors [25, 27].

It is also interesting that our research showed that higher education is not associated with a more interactive model, given that many studies have shown other facets of genetic knowledge to be associated with higher education [42]. Because prior research has shown that even highly educated people tend to have low numeracy skills [43], future research might explicitly measure numeracy to more precisely assess whether differences exist along these dimensions.

Second, the results suggest that the mathematical model and underlying causal accounting employed by many lay people may differ depending on whether the issue is understood as 'gaining' good health from good genes and good behaviors or 'losing' good health from weak genes and unhealthy behaviors. This may result from a general difference between gain and loss framing, but it also may be more specifically related to a tendency to understand genes primarily as causal factors for bad health and healthy behaviors as causal factors for good health outcomes. This difference may arise because good health is taken as normative and as a product of normal or typical genes, but this may also be related to a model in which genes are more powerful at causing bad health and behavior is more powerful in causing good health. The former explanation is consistent with a well-documented health optimism bias [44], but the latter may also be true and perhaps may be a product of news coverage, which typically links genes with disease [45].

Whether the former or latter (or both) explanations are correct may have implications for presenting information from personalized genetic testing in order to motivate behavior and for modes of teaching of gene-environment interaction. If this is simply a gain/loss frame issue, then the general recommendations for use of gain and loss framing would apply [46]. If, on the other hand, it results from differential assignment of outcomes to genes and to behaviors for disease as opposed to for normal health, this issue may have to be explicitly addressed in teaching the gene-behavior interaction concept and in messages about the implications and utilities of personalized genetic tests.

Such implications, however, presume that the measured difference between gain and loss messages is real, rather than an artifact of inadequate measurement approaches. We suggest that the consistency of this finding with previous qualitative findings on the variation of health accounting, resulting from motivational effects $[25,32]$ and with the larger research tradition on gain/ loss framing [46], weighs in favor of the conclusion that the questions are detecting a substantive difference in response. The fact that both the recommended additive/ amplificative test questions (R.J./C.W.) detect it and that the less parsimonious 'Emmeline/Sarah' questions using a different format (ranking) detect it as well, also weighs in favor of such an interpretation. However, one limitation may be that the gain framed question (which always followed the loss framed question, although other questions were randomized in order) does not explicitly use the $20 \%, 20$ numbers in the stem. A version of that question using those numbers and separated from the loss framed (R.J.) question should be tested to ensure that the difference in that question pair is not a result of the exclusion of the numbers in that case.

Third, the Gene-Behavior Interaction Beliefs Scale reported here meets the psychometric tests for good scale 
qualities. However, the level of public agreement with the gene-environment interaction concept as measured by the scale is greater than the level of agreement as measured by the more concrete additive/amplificative test questions, and the correlation between the two is low (approximate $r<0.10$ ). It may be that this weak correlation reflects an insufficiency in one or the other measurement approaches. Further research to validate the 2 scales may reveal ways in which one or the other is superior. Validation efforts might proceed via a close comparison of the scales with lay qualitative responses through cognitive interviewing. It may also prove that one or the other scales is more predictive of health behavior change, which would make it more useful, even if both detect substantive features of belief structures. Thus, using effectiveness rather than referential validity might provide the most desirable approach. Comparing the 2 approaches in studies assessing impact of genetic information on behavioral intentions would, in that case, provide the appropriate approach to validation.

It may also be that the inclusion of a specific disease (heart disease) in the additive/amplificative (R.J./C.W.) question pair and the reference to general diseases in the general scale is the cause of the difference. This possibility seems particularly worth exploring because existing surveys show sizeable differences in the role assigned to behavior and genes (independently) across different human outcome characteristics [13-15]. It may be that the public generally affirms an amplificative model for genebehavior relationships but in the case of heart disease specifically has an additive approach. Testing of the additive/ amplificative (R.J./C.W.) question pair using different diseases would illuminate this possibility.

In spite of the need to test these alternate possibilities, there is some reason to believe that perhaps the 2 different measurement approaches reflect a real schism between globalized beliefs that affirm the notion of gene-environment interaction in the abstract, but which do not apply the concept in concrete situations. In seeking to account for that possibility, we have discovered that such schisms between precise and concrete concepts and general diffuse beliefs seem likely to be undergirded by differences in what have been identified as 'qualitatively different representational frameworks' associated with abstract and concrete knowledge [47]. If this is the case, it has substantial consequences for the way in which teaching of the gene-behavior concept should go forward. Rather than concentrating on teaching the general idea (which the majority of people already appear to be able to affirm when it is presented to them abstractly), teaching may need to focus on applying the general idea to specific instances, including specific mathematical instances.

This line of explanation may also account for other message content choices. For example, it provides a plausible explanation for the superior performance of the 'elevator' metaphor over the 'bridge' metaphor in the research by Kaphingst et al. [29], as the elevator metaphor draws on pre-existing linkages between mathematical concepts (numbered floors and concepts of acceleration and deceleration related to numbers through driving), whereas the appearance of holes and patches in the bridge metaphor does not draw on a neural semantic network that contains previously established links among mathematical and concrete applications. On the other hand, this discrepancy may also or merely reflect the well-documented challenges of relating risk estimates to personal health issues [48]. Immediate research is needed to disentangle these potential causal factors.

Researchers are just making a beginning on understanding the complexities of human cognition necessary to translate the wealth of genetic information into forms that will allow people to maximize the utility of that information in their lives. This report provides some preliminary tools and findings toward that effort.

\section{Acknowledgements}

This research was supported by NIH grant \#HG003961-01. The authors thank Jamie Landau and Terry Kaley for manuscript preparation, and Dr. David Flannery, Dr. Tina M. Harris, Youyou Cheng, Lanelle Wright, Jamie Landau, Marita Gronnvoll, Bethany Keeley, Nicole Hurt, Angela Nowicki, and Marcus Coleman for their contributions to survey development. They are deeply grateful to their Community Advisory Board members and their research participants for their time and contributions.

References

Public Health Genomics 2011;14:115-124 123
1 Collins FS: The future of genomics. Testimony before the subcommittee on Health Committee on Energy and Commerce. United States House of Representatives, Washington, DC, May 2003.

2 Goddard KA, Duquette D, Zlot A, Johnson J, Annis-Emeott A, Lee PW, Bland MP, Edwards KL, Oehlke K, Giles RT, Rafferty A, Cook ML, Khoury M: Public awareness and use of direct-to-consumer genetic tests: results from 3 state population-based surveys, 2006. Am J Public Health 2009;99:442-445.

3 Kolor K, Liu T, St. Pierre J, Khoury MJ: Health care provider and consumer awareness, perceptions, and use of direct-to-consumer personal genomic tests, United States, 2008. Genet Med 2009;11:595.

Public Understanding of 
4 GenomeWeb Daily News: Toronto Clinic to offer Navigenics service. July 24, 2009. http://www.genomeweb.com//node/920978? $\mathrm{emc}=\mathrm{el} \& \mathrm{~m}=449778 \& \mathrm{l}=2 \& \mathrm{v}=42 \mathrm{c} 8152690$ (accessed September 22, 2009).

5 Heshka JT, Palleschi C, Howley H, Wilson B, Wells PS: A systematic review of perceived risks, psychological and behavioral impacts of genetic testing. Genet Med 2008;10:19-32.

-6 Smerecnik CM, Mesters I, de Vries NK, de Vries H: Educating the general public about multifactorial genetic disease: applying a theory-based framework to understand current public knowledge. Genet Med 2008;10 251-258.

7 Condit CM: Public understandings of genetics and health. Clin Genet 2010;77:1-9.

$\checkmark 8$ Gray SW, O'Grady C, Karp L, Smith D, Schwartz JS, Hornik RC, Armstrong K: Risk information exposure and direct-to-consumer genetic testing for BRCA mutations among women with a personal or family history of breast or ovarian cancer. Cancer Epidemiol Biomarkers Prev 2009;18:1303-1311.

-9 Hay JL, Meischke HW, Bowen DJ, Mayer J, Shoveller J, Press N, Asgari M, Berwick M, Burke W: Anticipating dissemination of cancer genomics in public health: a theoretical approach to psychosocial and behavioral challenges. Ann Behav Med 2007;34:275286.

10 Haga SB: Teaching resources for genetics. Nat Rev Genet 2006;7:223-228.

- 11 Meiser B, Irle J, Lobb E, Barlow-Stewart K: Assessment of the content and process of genetic counseling: a critical review of empirical studies. J Genet Couns 2008;17:434-451.

-12 Walter FM, Emery J, Braithwaite D, Marteau TM: Lay understanding of familial risk of common chronic diseases: a systematic review and synthesis of qualitative research. Ann Fam Med 2004;2:583-594.

13 Bates BR, Templeton A, Achter PJ, Harris TM, Condit CM: What does 'A gene for heart disease' mean? A focus group study of public understandings of genetic risk factors. Am J Med Genet 2003;119A:156-161

14 Parrott R, Silk K, Weiner J, Condit C, Harris $\mathrm{T}$, Bernhardt J: Deriving lay models of uncertainty about genes' role in illness causation to guide communication about human genetics. J Commun 2004;54:105-122.

15 Singer E, Corning AD, Lamias M: The pollstrends: genetic testing, engineering, and therapy. Public Opin Q 1998;62:633-664.

16 Khoury M, Wacholder S: Invited commentary: from genome-wide association studies to environment-wide interaction studies challenges and opportunities. Am J Epidemiol 2009;169:227-230.

17 Munafò MR, Flint J: Replication and heterogeneity in gene $\mathrm{X}$ environment interaction studies. Int J Neuropsychopharmacol 2009; 12:727-729.
Risch N, Herrell R, Lehner T, Liang K, Eaves L, Hoh J, Griem A, Kovacs M, Ott J, Merikangas KR: Interaction between the serotonin transporter gene (5-HTTLPR), stressful life events, and risk of depression: a meta-analysis. JAMA 2009;301:2462-2471.

19 Thapar A, Harold G, Rice F, Langley K, O’Donovan M: The contribution of gene-environment interaction to psychopathology. Dev Psychopathol 2007;19:989-1004.

20 Zubrick SR, Silburn SR, Burton P, Blair E: Mental health disorders in children and young people: scope, cause and prevention. Aust N Z J Psychiatry 2000;34:570-578.

21 Sing CF, Stengard JH, Kardia SL: Genes, environment and cardiovascular disease. Arterioscler Thromb Vasc Biol 2003;23:11901196.

$22 \mathrm{Wu}$ X, Jin L, Xiong M: Mutual information for testing gene-environment interaction. PLoS One 2009;4:e4578.

23 Silberberg JS: Estimating the benefits of cholesterol lowering: are risk factors for coronary heart disease multiplicative? J Clin Epidemiol 1990;43:875-879.

24 Cheng Y, Condit CM, Flannery D: Depiction of gene-environment relationships in online medical recommendations. Genet Med 2008;10:450-456.

25 Condit CM, Gronnvoll M, Landau J, Shen L, Wright L, Harris TM: Believing in both genetic determinism and behavioral action: a materialist framework and implications. Public Underst Sci 2009;18:730-746.

26 French DP, Marteau TM, Senior V, Weinman J: Perceptions of multiple risk factors for heart attacks. Psychol Rep 2000;87:681-687.

27 Gronnvoll M, Landau J: From viruses to Russian roulette to dance: a rhetorical critique and creation of genetic metaphors. Rhetor Soc Q 2010;40:46-70.

28 Kaphingst KA, Persky S, McCall C, Lachance $\mathrm{C}$, Beall AC, Blascovich J: Testing communication strategies to convey genomic concepts using virtual reality technology. J Health Commun 2009;14:384-399.

-29 Kaphingst KA, Persky S, McCall C, Lachance $\mathrm{C}$, Loewenstein J, Beall AC, Blascovich J: Testing the effects of educational strategies on comprehension of a genomic concept using virtual reality technology. Patient Educ Couns 2009;77:224-230.

30 Horowitz J: Media portrayals and health inequalities a case study of characterizations of gene $\mathrm{X}$ environment interaction. J Gerontol B Psychol Sci Soc Sci 2005;60:S48S52.

31 Morris J, Gwinn M, Clyne M, Khoury MJ: Public knowledge regarding the role of genetic susceptibility to environmentally induced health conditions. Community Genet 2003;6:22-28.

32 Hampson SE, Andrews JA, Lee ME, Foster LS, Glasgow RE, Lichtenstein E: Lay understanding of synergistic risk: the case of radon and cigarette smoking. Risk Anal 1998;18: 343-350.
Hermand D, Mullet E, Coutelle B: Perception of the combined effect of smoking and alcohol on health. J Soc Psychol 2001;135: 167-174.

34 Eiser JR, Reicher SD, Podpadec TJ: Smokers and non-smokers' estimates of their personal risk of cancer and of the incremental risk attributable to cigarette smoking. Add Res 1995;3:221-229.

35 Hampson SE, Andrews JA, Barckley M, Lee ME, Lichtenstein E: Assessing perceptions of synergistic health risk: a comparison of two scales. Risk Anal 2003;23:1021-1029.

36 Kühberger A: The influence of framing on risky decisions: a meta-analysis. Organ Behav Hum Decis Process 1998;75:23-55.

37 Shen L, Dillard JP: Message frames interact with motivational systems to determine depth of message processing. Health Commun 2009;24:504-514.

- 38 Shen L, Condit C, Wright L: The psychometric property and validation of a fatalism scale. Psychol Health 2009;24:597-613.

- 39 Lynch J, Bevan J, Achter P, Harris T, Condit CM: A preliminary study of how multiple exposures to messages about genetics impact on lay attitudes towards racial and genetic discrimination. New Genet Soc 2008;27:43-56.

40 Helm B: Online polls: how good are they? Business Week, June 5, 2008. http://www. businessweek.com/magazine/content/08_24/ b4088086641658.htm (accessed September 22, 2009).

41 Krosnick J, Rivers D, Nie N: Comparing major survey firms in terms of survey satisficing: telephone and internet data collection. American Association for Public Opinion Research, 2005, p 1.

42 Kalfoglou A, Suthers K, Scott J, Hudson K: Reproductive genetic testing: what America thinks. Washington, D.C., Genetics and Public Policy Center. 2004. http://www. dnapolicy.org/pub.reports.php (accessed August 26, 2009).

43 Lipkus IM, Samsa G, Rimer BK: General performance on a numeracy scale among highly educated samples. Med Decis Making 2001; 21:37-44.

44 Harris PR, Griffin DW, Murray S: Testing the limits of optimistic bias: event and person moderators in a multilevel framework. J Pers Soc Psychol 2008;95:1225-1237.

45 Petersen A: Illness frame for genes news' biofantasies: genetics and medicine in the print news media. Soc Sci Med 2001;52:1255-1268.

-46 Keller PA, Lipkus IM, Rimer B: Affect, framing, and persuasion. J Market Res 2003;40: 54-64.

47 Crutch SJ, Connell S, Warrington EK: The different representational frameworks underpinning abstract and concrete knowledge: evidence from odd-one-out judgments. Q J Exp Psychol 2009;62:1377-1390.

48 Lipkus IM: Numeric, verbal, and visual formats of conveying health risks: suggested best practices and future recommendations. Med Decis Making 2007;27:696-713. 